ARCHIVO ESPAÑOL DE ARTE, LXXXVI, 342

ABRIL-JUNIO 2013, pp. 123-142

ISSN: 0004-0428

\title{
LA PINTURA DE FLORES DE MIGUEL PARRA (1780-1846)
}

\author{
María José LóPEz TERRADA \\ Universitat de València
}

\begin{abstract}
Aunque Miguel Parra Abril (Valencia, 1780-Madrid, 1846) es uno de los pintores de flores más importantes de la Escuela valenciana, esta faceta pictórica de su producción es todavía poco conocida. El presente artículo trata de paliar esta situación ofreciendo, en primer lugar, una visión general de su obra como pintor de flores desde su proceso de aprendizaje en la Academia de Bellas Artes valenciana hasta sus composiciones de madurez. En segundo lugar, se presenta el análisis de dos composiciones florales inéditas y su relación con las obras conocidas hasta el momento, especialmente con aquellas que hasta hace pocos años se encontraban en colecciones particulares.
\end{abstract}

Palabras clave: Miguel Parra; Pintura de flores; Siglo XIX; Academia de Bellas Artes de Valencia; Colecciones reales; Coleccionismo privado; Obras inéditas.

THE FLOWER PAINTINGS OF MIGUEL PARRA (1780-1846)

Although Miguel Parra Abril (Valencia, 1780-Madrid, 1846) is one of the most important Valencian School painters of floral still lifes, this aspect of his work remains little known. The present article addresses this oversight in two ways. First, by offering an overview of his oeuvre as a painter of floral subjects from his student days at the Fine Arts Academy of Valencia through his mature works. Second, by analyzing two heretofore-unpublished floral compositions in relation to his more familiar works, particularly those located in private collections until recent years.

Key words: Miguel Parra; Floral paintings; $19^{\text {th }}$ century; Fine Arts Academy of Valencia; Royal collections; Private collecting; Unpublished works.

Miguel Parra Abril (Valencia, 1780-Madrid, 1846) figura entre los artistas más relevantes y conocidos de la Escuela valenciana de Flores. El origen de esta Escuela fue la Sala de "Flores, Ornatos y otros diseños adecuados para los Tejidos", que comenzó a funcionar en la Real Academia de Bellas Artes de San Carlos en el año 1778. Su creación estuvo determinada por la necesidad de formar pintores especializados en el diseño textil capaces de crear modelos originales que asegurasen la independencia y el desarrollo de las sederías valencianas respecto a las francesas. Esta Sala se convirtió en la Escuela de Flores y Ornatos seis años más tarde, a partir de la Real Orden de 1784. En ella, Carlos III equiparó estos estudios de forma oficial en rango, dotación y dignidad con las restantes enseñanzas académicas, nombrando como director al "Maestro 
de Flores" Benito Espinós (1748-1818)․ La Escuela valenciana de Flores, que continuó funcionando hasta 1855, sólo logró convertirse parcialmente en un estímulo para la industria textil. Sin embargo, formó a un excelente grupo de pintores de flores, entre los que destacó muy tempranamente Miguel Parra.

El objetivo del presente artículo es contribuir al conocimiento todavía insuficiente de esta faceta pictórica de su producción mediante dos vías. La primera ofrece una visión general de la obra de Miguel Parra como pintor de flores desde su proceso de aprendizaje en la Academia de Bellas Artes valenciana hasta sus composiciones de madurez. En esta visión general se considera tanto el proceso seguido por el artista para realizar sus obras y su sentido estético en el marco académico, como la repercusión que tuvo el cultivo de este género en su calidad de Pintor Honorario de Cámara. La segunda se centra en el análisis de dos composiciones florales inéditas y su relación con las obras conocidas hasta el momento, especialmente con aquellas que hasta hace pocos años se encontraban en manos de coleccionistas particulares.

Miguel Parra Abril comenzó su formación en la Sala de Principios de la Academia de Bellas Artes de San Carlos a los trece años y no a los doce, como se venía manteniendo hasta el momento. Así lo indica el propio artista en una relación de sus méritos que envía a la Junta de la Academia en 1810 en la que afirma que:

“... desde la edad de trece años principió su carrera de Dibuxo, destinándose luego al ramo de flores, ornatos y fábrica, en cuyo Estudio obtuvo varios premios mensuales, pensiones y los tres premios generales de $3^{\mathrm{a}}, 2^{\mathrm{a}}$ y $1^{\mathrm{a}}$ clase, y continuando con su estudio le condecoró esta Real Academia, ha muy poco tiempo, con el título de Académico de Mérito, en 10 de julio de 1803, en la referida clase"2.

Hasta el momento, no se ha podido localizar ningún dibujo de su paso por la Sala de Principios ni noticias relativas a los "varios premios mensuales y pensiones" que Parra recibió en la Sala de Flores, pero parece oportuno detenerse en lo que suponía para un artista tan joven alcanzar los reconocimientos que menciona en los Concursos Generales que corresponden a los años 1795, 1798 y 1801.

Al igual que los premios mensuales y las pensiones, las cantidades en metálico o gratificaciones entregadas en los Concursos Generales eran un medio para juzgar la aplicación y el talento de los discípulos de la Academia, pero tenían un carácter público, pues se distribuían entre las diferentes instituciones artísticas del país. En las convocatorias de estos concursos trienales se daban a conocer las normas, los temas y los plazos estipulados para cada una de las clases de la Academia, entre la que se encontraba la de Flores. Las obras que los opositores debían presentar eran de dos tipos. Los primeros asuntos que se determinaban y se hacían públicos constituían los ejercicios "de pensado". Tras ser examinados en la Junta General correspondiente se acordaban los temas para los ejercicios "de repente", que debían llevarse a cabo en la Academia. Se disponía para ello de dos horas y los dibujos se realizaban en papeles iguales, rubricados por el secretario y no se firmaban. Los tres premios que correspondían a cada clase se adjudicaban a partir de los votos obtenidos y se entregaban en una Junta Pública convocada para ello.

El Concurso General de 1795, el primero en el que Miguel Parra fue premiado con tan sólo quince años, es especialmente interesante, pues conocemos no sólo los temas con los que participó,

\footnotetext{
${ }^{1}$ Entre los trabajos dedicados a esta Escuela se encuentran las obras de AldANA Fernández, 1970a y LóPez TerRAdA, 2001, donde se recoge la bibliografía anterior. La última aportación corresponde a SÁNCHEZ LóPEZ, 2008, principalmente la parte que dedica a "Las manufacturas y su importancia en el desarrollo del género en Valencia": 310-355, dentro de un necesario análisis sobre la pintura de bodegones y floreros españoles del siglo XVIII.

${ }^{2}$ Miguel Parra hace relación de sus méritos y recompensas pidiendo a la Junta de la Academia, tema para obtener el grado de Académico de Mérito, 1 de diciembre de 1810, Archivo de la Academia de Bellas Artes de San Carlos de Valencia, Varios, no 68. Reproducido por Aldana FernÁndez, 1970a: 282-283.
} 


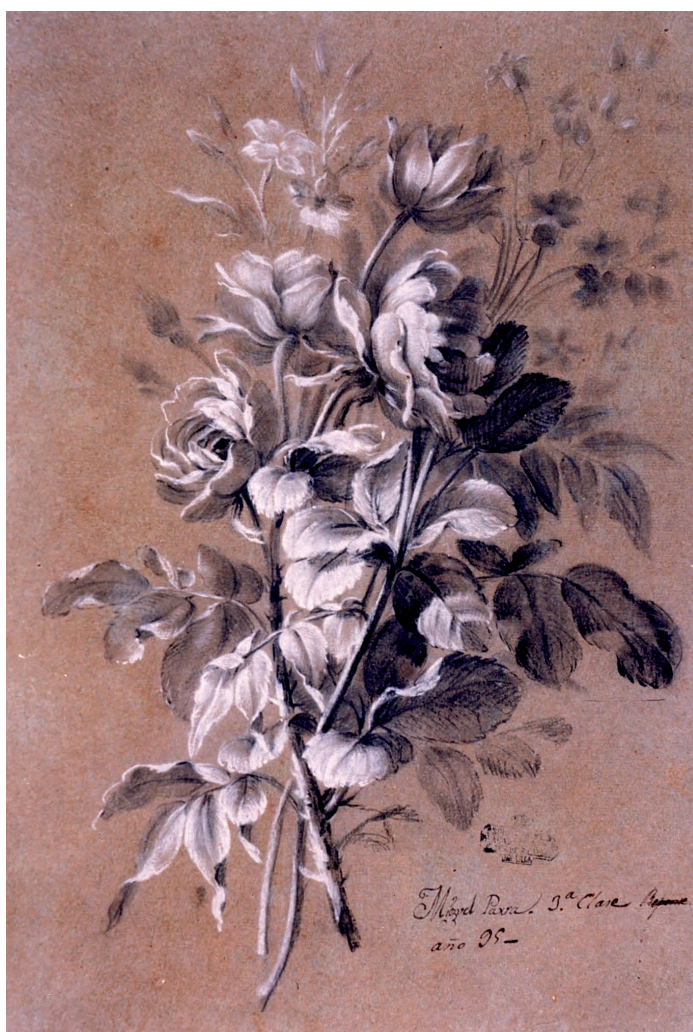

Fig. 1. Miguel Parra, Estudio de flores, 1795. Museo de Bellas Artes de Valencia.

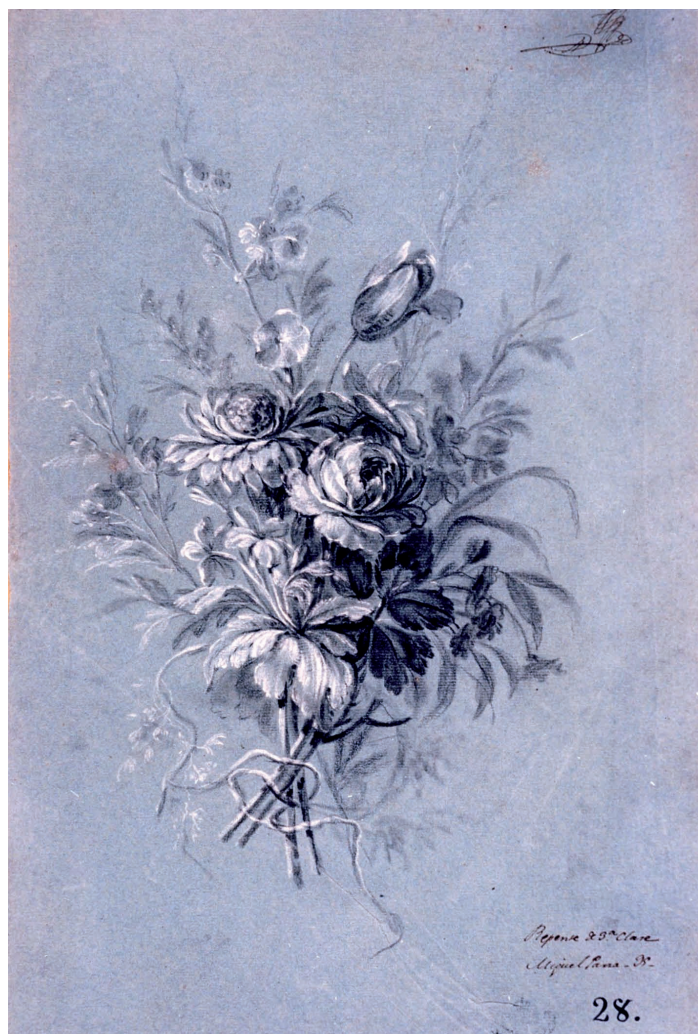

Fig. 2. Miguel Parra, Estudio de flores, 1795. Museo de Bellas Artes de Valencia.

sino también algunas de las obras que realizó para el mismo. Tal como se recoge en las Actas de la Academia $^{3}$, el asunto de pensado que debían realizar los aspirantes a la tercera clase de la Sala de Flores, dotada con un premio de 10 pesos, consistía en "un abundante estudio copiado del natural". El ejercicio "de repente", que compartían tanto los de segunda como los de tercera clase, debía de tratarse de un trabajo similar, aunque a partir de los "Varios jarros con flores naturales que había prevenidos á este fin".

El Museo de Bellas Artes de Valencia conserva dos de los dibujos por los que Miguel Parra fue galardonado en este concurso. Estos Estudios, realizados con lápiz negro y tiza sobre papel verjurado, son las primeras obras de flores conocidas del artista ${ }^{4}$. El primer Estudio (fig. 1), de $40,1 \times 28,2 \mathrm{~cm}$, es un ramo compuesto por tres hermosas rosas con sus correspondientes tallos

${ }^{3}$ Continuación de las Actas de la Real Academia de las Nobles Artes establecida en Valencia con el título de San Carlos, y relación de los premios que distribuyó en su Junta pública de 6 de noviembre de 1795. En Valencia, en la oficina de Benito Monfort, impresor de la Real Academia. Año 1796, p. 10 y ss.

${ }^{4}$ Estos Estudios de flores, dados a conocer en el trabajo de Aldana Fernández, 1970a, nº 259, y 259, fueron reproducidos por primera vez en el estudio de Espinós DíAz, 1997: 101, donde figuran respectivamente con los números 1352 A. E. (fig. 13) y 1456 A. E. (fig. 14), dentro de su amplio análisis de los premios de la Clase de Flores de los Concursos Generales. Actualmente se conservan en el Museo de Bellas Artes de Valencia catorce dibujos de Miguel Parra realizados durante su época de estudiante en la Sala de Flores. 
y hojas, un tulipán abierto, jazmines reales y prímulas. Está firmado y fechado, indicándose además en el ángulo inferior izquierdo que se trata de un dibujo para la tercera clase de flores, pero no un "repente", palabra que aparece tachada. En el segundo (fig. 2), de 52,9 ×33,4 cm, sí se indica claramente que se trata de un "repente de tercera clase". En este caso, Parra representó un ramo más complejo con prímulas, una rosa, un crisantemo, un tulipán, jazmines, malvas reales y margaritas. Este dibujo es especialmente interesante porque en él figura el número 28, cifra que ha permitido identificarlo en la relación del Inventario de la Academia realizado entre 1797 y 1834 como:

"Otro medio pliego azul en que se halla dibujado un grupo de flores copiado del natural, dado por asunto en la tercera clase de dichos premios generales del 95 y éste se halla reunido con otros siete papeles que son: un jarrón dibujado de lápiz encarnado, un grupo de flores pintado de aguadas, cuatro papeles sobre papel pardo de varios adornos para texidos pintados igualmente a aguadas; y sobre papel azul dibujado otro grupo de flores. Por todos ellos y por un florero al óleo bajo el número 16 se le adjudicó dicho tercer premio a Miguel Parra"

En las Juntas donde se entregaban públicamente los premios de los Concursos Generales se recitaban además discursos y poesías, en los que no solían faltar los elogios a la Academia de Bellas Artes y a sus protectores, el recuerdo a la historia artística valenciana o las directrices que debían seguir los alumnos de esta institución ${ }^{6}$. Por la relación que guarda con estas primeras obras de Parra, y por la excepcionalidad que representa dentro de la mentalidad académica, más inclinada al idealismo, parece oportuno reproducir un fragmento del discurso escrito para la ocasión por Don Pedro de Silva Meneses en esta entrega de premios?:

"Estudie pues el Artista los célebres Maestros día y noche, como aconseja Horacio (o) los exemplares griegos para perfeccionarse. Pero estudie incesantemente la Naturaleza, y encontrará siempre en ella, además de la verdad siempre constante, una variedad siempre varia, y siempre arreglada y juiciosa. Aun vosotros ingeniosos Jóvenes, que dedicados al fomento de las Fabricas, buscáis en vuestros dibuxos la novedad, que por nuestra desdicha es el único mérito que se considera en los texidos; aun vosotros encontraréis en la verdad de la Naturaleza esa misma novedad que apetecéis. Con razón os presenta la Academia hermosas macetas de naturales flores, persuadida de que en la verdad de estos matizados entes con que esmaltó sabia la Naturaleza los campos, aprenderéis á presentar en las telas unos dibuxos que sorprendan, y muestren novedad, e invención en su misma naturalidad; la contraposición de varias flores muy conocidas cada una de por sí, producirá un todo que herirá con novedad y sorpresa la vista de quienes le miren"».

La imitación o representación de las flores directamente del natural constituía no solamente un ejercicio de los Concursos Generales, sino también la primera fase de las enseñanzas de los discípulos de la Sala de Flores. En la Real Orden de 1784 por la que se estableció de forma definitiva la Escuela de Flores y Ornatos en la Academia se determinaba que durante los meses

\footnotetext{
${ }^{5}$ Inventario general de las Pinturas, Flores pintadas y dibujadas. Modelos y Vaciados, Dibujos de todas clases, y Diseños de Arquitectura. Y también de las obras pertenecientes al ramo del Grabado de los libros e Impresiones, con alguna noticia de su execución y adquisición: últimamente de los Muebles, Alhajas y demás que posee esta real academia de San Carlos. Hecho en el año 1797, por el secretario de la misma y algunos de sus más celosos Directores (continuado hasta el año 1834). Ver Espinós DíAz, 1997: 101, nota 33.

${ }^{6}$ Las ideas estéticas contenidas en este tipo de fuentes fueron estudiadas por León Tello; SANZ SAnZ, 1979.

${ }^{7}$ Don Pedro de Silva Meneses, que ocupó importantes cargos en la Corte, fue uno de los primeros académicos de honor de la Real Academia de Bellas Artes de San Carlos (27 de marzo de 1768). Sus ideas estéticas son analizadas en el estudio ya mencionado de León Tello; SANZ SANZ, 1979: 139-144.

${ }^{8}$ Continuación de las Actas de la Real Academia de las Nobles Artes establecida en Valencia con el título de San Carlos, y relación de los premios que distribuyó en su Junta pública de 6 de noviembre de 1795. En Valencia, en la oficina de Benito Monfort, impresor de la Real Academia. Año 1796: 38-39.
} 
de primavera, desde el 1 de abril al 31 de julio, sus alumnos debían dedicar dos horas diarias por la mañana al estudio de las flores del natural, realizando dibujos a lápiz, "y otros de colorido al pastel, o aguadas o al óleo". Es interesante destacar que las flores que los alumnos tomaban como modelo eran aquellas "que producen el tiempo en estos cuatro meses" y quedaba a cargo de la Academia "costear y tener prontas las flores que pidiese el mismo Director en dichos cuatro meses". En 1788, este turno de trabajo se alteró, estableciéndose el inicio de las clases en marzo y finalizándolas en julio "por haber enseñado la experiencia que las flores que presenta la estación, por su mucha variedad, son más a propósito al expresado fin que las que hay en el dicho julio y en particular las de los frutales, que después no las hay y ser éstas muy al caso para el fin a que se estableció dicho Estudio"'.

Estos estudios tomados directamente del natural no sólo se convertían, convenientemente adaptados, en los motivos principales de los diseños textiles, sino que eran también utilizados para componer los cuadros de flores propiamente dichos. No obstante, la enseñanza que se impartía en la Academia no podía limitarse a la simple mímesis de los elementos vegetales. Durante la temporada de invierno, que se iniciaba en septiembre y terminaba en marzo, las clases, también de dos horas, se impartían por la noche y en ellas, los estudiantes debían "copiar los originales dibujados y coloridos", siendo obligación del Director "ordenar y hacer por sí un estudio de flores, sacadas del natural, y ayudadas de realces del buen gusto y de los adornos; para los cuales la Academia le facilitará las lochas de Rafael, y otros ejemplares de los preciosos restos de la Antigüedad que deberán servirle exclusivamente de norma, a fin de ir formando el gusto a los discípulos" ${ }^{\prime \prime}$. Esta última indicación responde a los nuevos criterios académicos que consideraron las alusiones a la Antigüedad clásica como parte fundamental de los "adornos de buen gusto" que debían acompañar a la representación de las flores. Por esta razón, en muchas obras de esta Escuela, incluidas las de Parra, los arreglos florales se disponen junto a bajorrelieves y otras piezas de arqueología, como pedestales de mármol o fragmentos de columnas.

Como se ha adelantado, Miguel Parra resultó galardonado en el Concurso General de 1798 con el premio de 20 pesos de la segunda clase de Flores. En esta ocasión el tema establecido como "ejercicio de pensado" era "Un Dibuxo para un Paño de hombros, por el mismo estilo de las Lochas, arreglado a fábrica de raso; y un Florero pintado al óleo, o al agua"; mientras que el "repente" consistía en "Dibuxar en un palmo y quarto de largo una Cenefa, para un vestido de Señora, con el reporte correspondiente, y por el mismo estilo del de la primera clase", que se refería nuevamente a las Logias de Rafael ${ }^{11}$. El Museo de Bellas Artes de Valencia conserva cuatro de los dibujos que el artista realizó para este Concurso ${ }^{12}$, aunque no se tiene noticias del Florero. A pesar de esta ausencia, podemos saber lo que se esperaba y valoraba de este tipo de composiciones florales si las ponemos en relación con los discursos y poesías pronunciados en la entrega de premios de aquel año.

A diferencia del naturalismo propuesto por Don Pedro de Silva Meneses en 1795, los conceptos contenidos en el parlamento del académico Nicolás Rodríguez de Laso ${ }^{13}$ se corresponden de una manera mucho más fiel con el procedimiento seguido por los pintores de flores a la hora de componer sus arreglos florales. Siguiendo la formulación de la teoría de la idealización más conocida y practicada desde la Antigüedad, afirma:

\footnotetext{
9 Aldana Fernández, 1970: 81-82

${ }^{10}$ López Terrada, 2001: 132.

${ }^{11}$ Continuación de las Actas de la Real Academia de las Nobles Artes establecida en Valencia con el título de San Carlos, y relación de los premios que distribuyó en su Junta pública de 6 de diciembre de 1798. En Valencia, por D. Benito Monfort, impresor de la Real Academia, año 1799: 14-26

${ }^{12}$ Véase Espinós DíAz, 1997: 241-244, donde se identifican y reproducen tres modelos para tejido y el "ejercicio de repente" para este concurso.

${ }^{13}$ LeÓn Tello; SAnZ SAnZ, 1979: 145-150.
} 
"Si: la naturaleza, ya os lo he dicho, es nuestra Maestra; ella no permite, si la seguimos lealmente, que nuestros pasos se extravíen por los senderos de la imaginación desenfrenada y sin orden: pero la naturaleza atenta solamente á formar harmonía acorde de un todo, no esculpe en cada una de sus partes otra belleza que la que le es necesaria á sus fines. Sus partes consideradas en sí mismas no presentan tal vez mas que una belleza relativa; y el Artífice que procurase imitarla servilmente sería un Artífice estéril, y sin riqueza de imágenes. Este es un escollo en que fácilmente se estrellan los medianos ingenios. Esta es una advertencia jamás bastantemente inculcada por los más sagaces [...] el Artista docto, y enamorado de la verdadera belleza, imitará a la naturaleza en su orden y disposición harmoniosa; pero la hará como hemos dicho más bella con su imaginación fecunda; tomará de cada una de sus partes aquella gracia, aquel espíritu, aquella actitud, que forma un nuevo todo, un nuevo complexo ideal de seres bellos y maravillosos [...] Esto es lo que llamamos belleza ideal ${ }^{14}$.

De la misma forma que los discursos académicos repetían los viejos tópicos de la historia de Zeuxis para ilustrar la teoría de la idealización, las poesías incluían a menudo otras imágenes referidas específicamente a la pintura de flores. Uno de los ejemplos más claros es la poesía recitada en este Concurso por Don Pedro Pichó y Rius ${ }^{15}$. Su referencia al ilusionismo, que tuvo su origen en el duelo de Zeuxis y Parrasio, ya había sido aplicada en el siglo XVII a pintores especializados en este género pictórico, como el artista madrileño Juan de Arellano. En un fragmento de sus Endecasílabos, el académico valenciano dice:

"Explica la estructura de esta rosa...

Mas jay! Nueva Ilusión. Ni Flora misma

Más fresca, más lozana y delicada

Pudiera en sus vergeles producirla.

Tuyo es este portento, pincel sabio,

Que al vivo en tus floreros imita

Toda la gracia, la belleza toda

Que muestra el campo en estación florida.

Tus hojas y tus flores embelesan,

Y tanta realidad halla la vista

En ellas, que el olfato seducido

La agradable fragancia solicita.

Mira, Naturaleza, en esos cuadros

Ríes tu abril, tu céfiro respira.

Venid alegres Genios, coged flores

Que ni cierzo, ni sol jamás marchitan"16.

Miguel Parra consiguió finalmente el premio de primera clase en Flores, dotado con 40 pesos, en el Concurso General de 1801. Realizó para ello "Un Dibuxo de una dalmática de Espolín, con su cenefa y adornos de buen gusto, por el termino de las Lochas de Rafael. Y un Florero de tres palmos y medio de alto y dos y medio de ancho, pintado al óleo o al agua". El ejercicio "de repente" consistía en este caso en "Un Dibujo para una cortina de Sagrario, demostrando solamen-

${ }^{14}$ Continuación de las Actas de la Real Academia de las Nobles Artes establecida en Valencia con el título de San Carlos, y relación de los premios que distribuyó en su Junta pública de 6 de diciembre de 1798. En Valencia, por D. Benito Monfort, impresor de la Real Academia, año 1799: 40.

15 LeÓn Tello; SAnZ SAnz, 1979: 251-254.

${ }^{16}$ Continuación de las Actas de la Real Academia de las Nobles Artes establecida en Valencia con el título de San Carlos, y relación de los premios que distribuyó en su Junta pública de 6 de diciembre de 1798. En Valencia, por D. Benito Monfort, impresor de la Real Academia, año 1799: 70. 
te la quarta parte" $" 17$. Como puede comprobarse, los temas a los que los opositores debían enfrentarse en ambos casos se ajustaban a los objetivos para los que se creó la Sala. La diferencia con los concursos anteriores es que en este caso, además de conservarse el "ejercicio de repente" ${ }^{\text {, }}$, sí se ha podido identificar entre los fondos de la Academia el lienzo por el que Parra consiguió en primer premio (fig. 3 ) $^{19}$.

Este óleo, que figura en el Museo de Bellas Artes de Valencia con el descriptivo título de Guirnalda de flores con una pintura en grisalla $y$ amorcillos pintando, fue calificado acertadamente como "una complicada composición de signo alegórico" ${ }^{20}$. Desde el punto de vista formal, puede considerarse un tipo de representación "clásico" de la pintura de flores, pues corresponde a la disposición específica de las plantas ornamentales en corona rodeando una escena de carácter religioso, realista o simbólico ${ }^{21}$. Esta tipología de origen flamenco alcanzó un amplio desarrollo en el siglo XVII, siendo empleada por muchos pintores de flores, incluidos los españoles. Es el caso de Juan van der Hamen (1596-1631), Antonio Ponce (1608-1677), Juan de Arellano (1614-1676) y, el propio Benito Espinós. La obra de Miguel Parra permite comprobar la pervivencia de este tipo de composición,

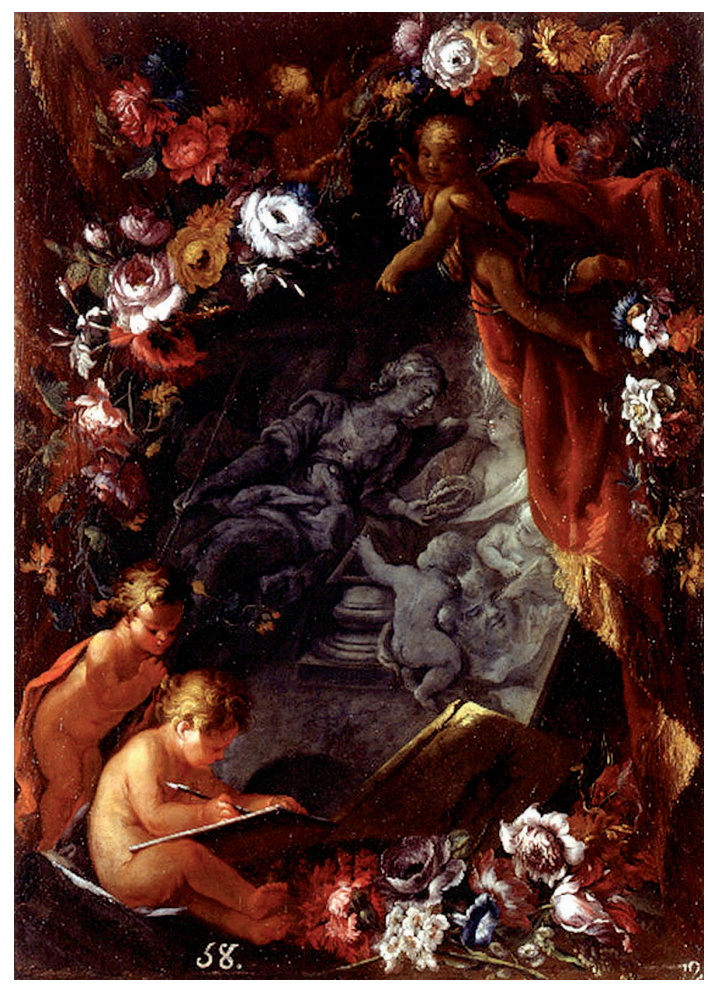

Fig. 3. Miguel Parra, Guirnalda de flores con una pintura en grisalla y amorcillos pintando, ca., 1810. Museo de Bellas Artes de Valencia. así como las novedades introducidas por la enseñanza académica. En este caso, el espacio central está ocupado por un lienzo en grisalla, definida en la época como "toda la pintura de color ceniciento de piedra, o de mármol blanco oscuro por la cual imitan las salidas, los compartimentos y otros adornos de Arquitectura y trozos de Escultura como baxo relieves" 22 . Como se ha adelantado, este tipo de elementos constituían los "adornos de buen gusto" que debían acompañar a los arreglos florales según los nuevos criterios académicos.

${ }^{17}$ Continuación de las Actas de la Real Academia de las Nobles Artes. Establecida en Valencia con el título de San Carlos, y relación de los premios que distribuyó en su junta pública de 12 de noviembre de 1801. En Valencia y oficina de D. Benito Monfort, impresor de la academia. Año MDCCCII. Rodríguez García, 1959: 176-177.

${ }^{18}$ Se trata de un dibujo realizado con lápiz negra y tinta sobre papel verjurado azul de $44 \times 30,6 \mathrm{~cm}$. Se reproduce y analiza en el estudio de Espinós Díaz, 1997: 245.

${ }^{19}$ Se trata de un óleo sobre lienzo de $80 \times 57 \mathrm{~cm}$ que fue donado por el autor a la Real Academia de Bellas Artes de San Carlos. Actualmente se conserva en el Museo de Bellas Artes de Valencia ( $\mathrm{n}^{\circ}$ de inventario 2047). Para un análisis más detallado de esta obra, ver LóPEZ TERRADA, 2008: 1-10.

${ }^{20}$ Pérez SÁnchez, 1996: 106. Este autor fue el responsable de identificar el lienzo con la obra premiada en el Concurso de 1801, cotejando el número 58 que puede verse en el lienzo con el Inventario ya citado de la Academia de 1797.

${ }^{21}$ Aunque el término preciso para designar el trenzado de flores con forma circular u oval es el de corona, la mayor parte de los historiadores del arte españoles se refieren a este tipo de composición como guirnalda. En realidad, esta palabra está reservada para el motivo ornamental formado por flores o frutos unidos por cintas, que se representa normalmente colgado de los extremos y combado hacia abajo. Sobre estas precisiones ver SEgAL, 1990: 16-18.

${ }^{22}$ MartíneZ, 1788: 228. 


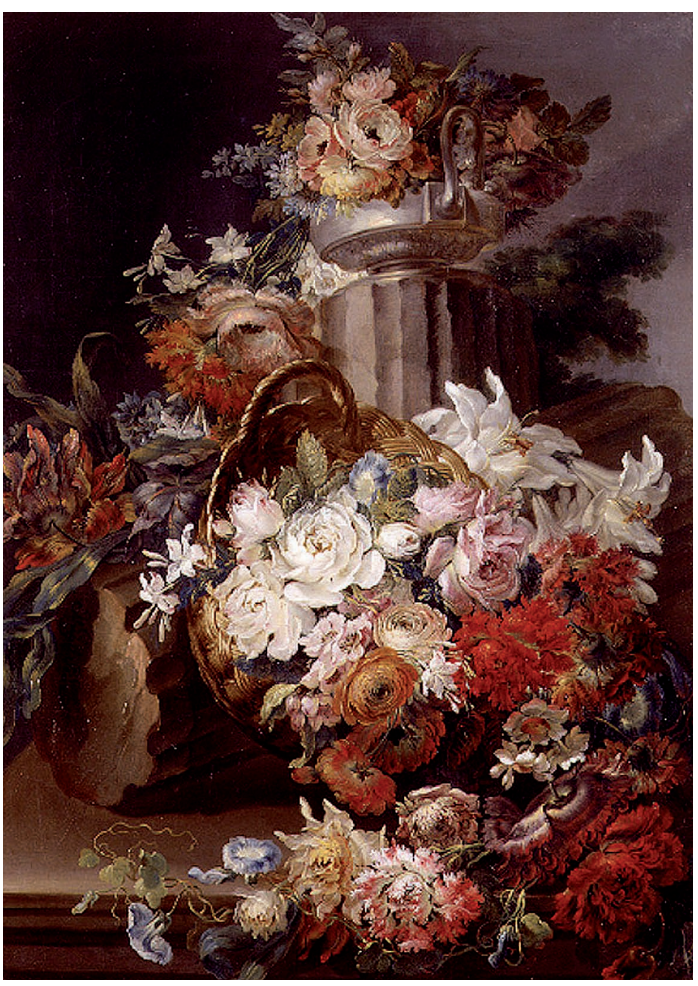

Fig. 4. Miguel Parra, Cesto de flores, ca. 1803. Museo de Bellas Artes de Valencia.
La figura femenina de esta escena central es la Virtud, que lleva tres coronas en la mano y se dirige a tres putti que representan respectivamente al genio de la Pintura, la Escultura y la Arquitectura. Delante de esta escena de grisalla, ocupando el primer plano, se dispone el genio del Diseño que alude a la importancia concedida al dibujo en la enseñanza académica y a su consideración como origen o punto de partida de todas las artes. La trascendencia del dibujo en los estudios de flores y ornatos aplicados a los tejidos también se refleja en la alegoría de Parra mediante la presencia de ejemplares cortados de clavel, adormidera, flores de cerezo, campanillas, anémonas y tulipanes que sirven de modelo al genio del Diseño. Ante un pesado cortinaje rojo, el resto de la variada decoración floral se dispone alrededor de la grisalla, adoptando la ya mencionada forma de corona oval que cierra un niño alado en la parte superior. Junto a él se representa el último elemento simbólico que completa el sentido de la composición. Se trata de la alegoría del Ingenio, que adopta la forma de un joven alado y que aparece señalando la escena central, donde la Virtud y el Conocimiento premian a las artes con la inmortalidad.

La siguiente obra conocida de Miguel Parra es muy posiblemente el cuadro que le valió el nombramiento de Académico de Mérito por la pintura de flores el 10 de julio de 1803 (fig. 4) ${ }^{23}$. Se trata de una compleja composición que viene determinada no sólo por la copiosa presencia de especies vegetales, sino también por la disposición espacial que utiliza para incluir las preceptivas alusiones a la Antigüedad, en este caso, dos fustes estriados de columnas. Sobre el superior, en sentido vertical, Parra ha situado un jarrón de estilo clásico lleno de flores, utilizando los tallos de las plantas que se desbordan para dirigir nuestra vista al cesto central, apoyado de forma inestable sobre el segundo fuste dispuesto en diagonal.

Este lienzo, que demuestra la total asimilación de las enseñanzas académicas, es además interesante por su repertorio floral, ya que en él pueden identificarse más de veinte especies botánicas diferentes que el artista utilizará con frecuencia en obras posteriores. Con una particular combinación de colores e iluminación, Parra suele reservar la parte más visible de sus arreglos para las rosas blancas (Rosa x alba L.) y rosas de Alejandría (Rosa damascena Mill.), que en este caso se rodean de jazmines reales (Jasminum grandiflorum (L.) Kabuski); flores de almendro (Prunus dulcis L.); francesillas (Ranunculo asiático L.) y claveles (Dianthus caryophyllus L.). A punto de caer del cesto y ocupando con su peso el primer plano, pero sin perder la continuidad, pueden distin-

${ }^{23}$ Esta posibilidad fue sugerida por PÉrez SÁnchez, 1996: 108 y desde entonces se ha mantenido en los estudios posteriores. Este óleo sobre lienzo mide $80 \times 57 \mathrm{~cm}$ y fue donado por el autor a la Real Academia de Bellas Artes de San Carlos. Actualmente figura entre los fondos del Museo de Bellas Artes de Valencia ( $\mathrm{n}^{\mathrm{o}}$ de inventario 551).

Arch. esp. arte, LXXXVI, 342, ABRIL-JUNIO 2013, 123-142, ISSN: 0004-0428 
guirse narcisos de manojo (Narcissus tazetta L.); adormideras (Papaver somniferum L.), una anémona doble (Anemone coronaria L.) narcisos dobles (Narcissus $x$ incomparabilis Mill.) y campanillas (Ipomoea tricolor Cav.). La cesta está flanqueada a la derecha por dos hermosas azucenas (Lilium candidum L.) y a la izquierda, por un tulipán abierto (Tulipa sp.). Otro grupo compacto de ejemplares de estas flores, entre los que destaca la amapola doble (Papaver rhoeas L.), permite la comunicación mediante sus tallos con el jarrón superior. Al igual que en el cesto, la parte central de este arreglo está más iluminada y se reserva para un manojo de anémonas y coronados (Callistephus chinensis (L.) Nees.), mientras que el fondo se completa con ramas de espuela de caballero (Consolida ambigua (L.) Ball \& Heyw.); de jazmín amarillo (Jasminum odoratissimum L.), rosas y adormideras.

Apenas comenzado el siglo XIX, tras ser nombrado Académico de Mérito por la Pintura de Flores con tan sólo veintitrés años, debió comenzar el prestigio de Parra como especialista en este género. Gracias al estudio de Aldana, sabemos que en 1810 envió cuatro floreros a México, "fecha en la cual ganaba por los encargos que recibía más de quinientos reales, casi tanto como los pintores ya consagrados" ${ }^{\prime 2}$. Sin abandonar esta actividad, que lo convertiría en uno de los pintores de flores y bodegones más apreciados de la época, continuó sus estudios en la Academia con la finalidad de convertirse en "Pintor de historia". Fue entonces cuando se convirtió en discípulo de Vicente López (1772-1850), que tanta influencia tendría en su fortuna posterior.

Sus aspiraciones se vieron pronto cumplidas, pues el 5 de agosto de 1811 alcanzó el grado de Académico de Mérito en Pintura. Su carrera docente comenzó un año más tarde, cuando fue nombrado Profesor auxiliar de la Clase de Pintura. No logró, sin embargo, conseguir la dirección de la Sala de Flores tras la jubilación de su maestro Benito Espinós en 1814, cargo que ocuparía José Antonio Zapata (1763-1837). Fue entonces, una vez finalizada la Guerra de la Independencia, cuando Parra decidió viajar a Madrid para conseguir el favor real, máxima aspiración de todo artista de la época. Al parecer, fue el propio Vicente López, que además de su maestro era ya entonces su cuñado ${ }^{25}$ y que había sido nombrado Primer Pintor de Cámara, quien se encargó de introducirle en la Corte. Con esta intención, Parra entregó al monarca el lienzo que representa $E l$ paso del río Fluviá por Fernando VII en su regreso a España, obra que le valió el nombramiento de Pintor Honorario de Cámara. Tras este primer lienzo, el artista realizó la Entrada triunfal de Fernando VII en Valencia y, gracias a la intervención de Vicente López, consiguió asegurar su vinculación a la Corte mediante el encargo de ejecutar otros cuadros del mismo carácter que completaran la serie de entradas triunfales de Fernando VII en 1814 y varios floreros. Estos lienzos los realizaría desde Valencia debido a sus obligaciones familiares y por ellos recibiría una pensión de 600 ducados anuales ${ }^{26}$. Fue una de estas obras, La entrada triunfal de Fernando VII en Zaragoza o una réplica de menor tamaño, junto a un cuadro y tres dibujos de flores actualmente no localizados, las que presentó a la Real Academia de Bellas Artes de San Fernando y le valieron el nombramiento de Académico de Mérito por la Pintura de Historia y por la Pintura de Flores de esta institución el 13 de noviembre de $1818^{27}$.

A partir de estas fechas, Miguel Parra desarrolló una intensa y variada actividad pictórica. Su relación con la Corte continuó gracias a Vicente López y, posteriormente, a su hijo Bernardo López, que actuaron como intermediarios y fueron los responsables de comunicarle nuevos

\footnotetext{
${ }^{24}$ Aldana, 1970: 103 y 109

${ }^{25}$ Miguel Parra se casó con Juliana Piquer, hermana de Vicenta Piquer, esposa de Vicente López. Archivo de Palacio Real. Expediente personal. Miguel Parra. Caja 791/14.

${ }^{26}$ Esta serie de entradas triunfales realizadas por Parra se analizan en su conjunto desde el punto de vista histórico artístico en el artículo de López Terrada; Alba Pagán, 2004.

27 Navarrete Martínez, 1999: 110. Sobre La entrada triunfal de Fernando VII en Zaragoza, ver López Terrada; Alba PagÁn, 2008.
} 


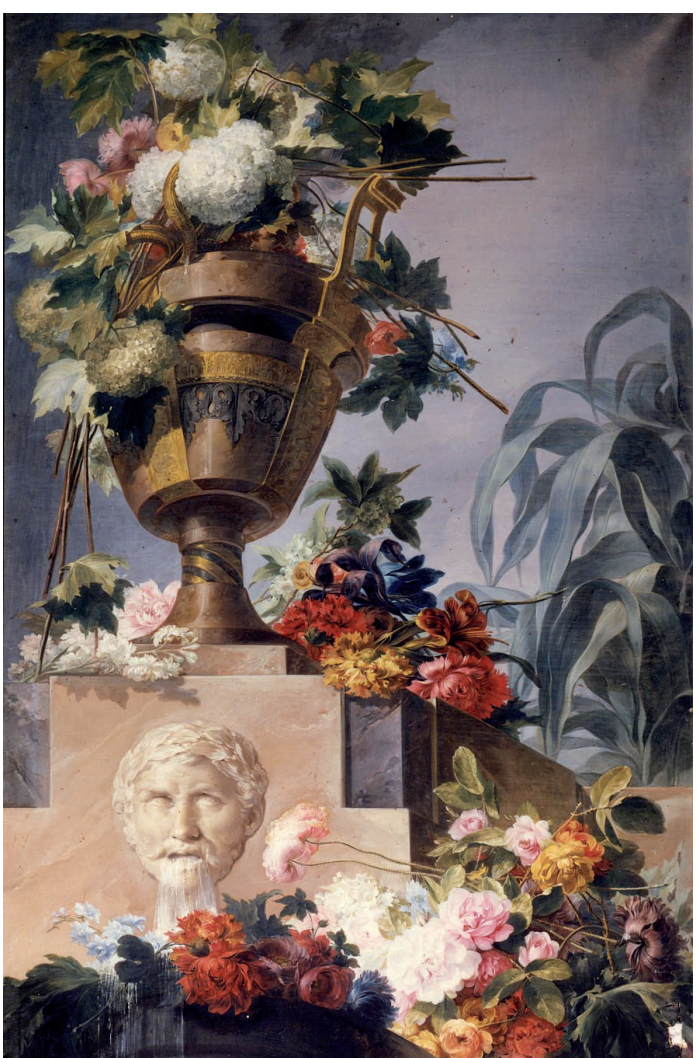

Fig. 5. Miguel Parra, Florero en un jardín, 1822. San Lorenzo de El Escorial, Casita del Príncipe.

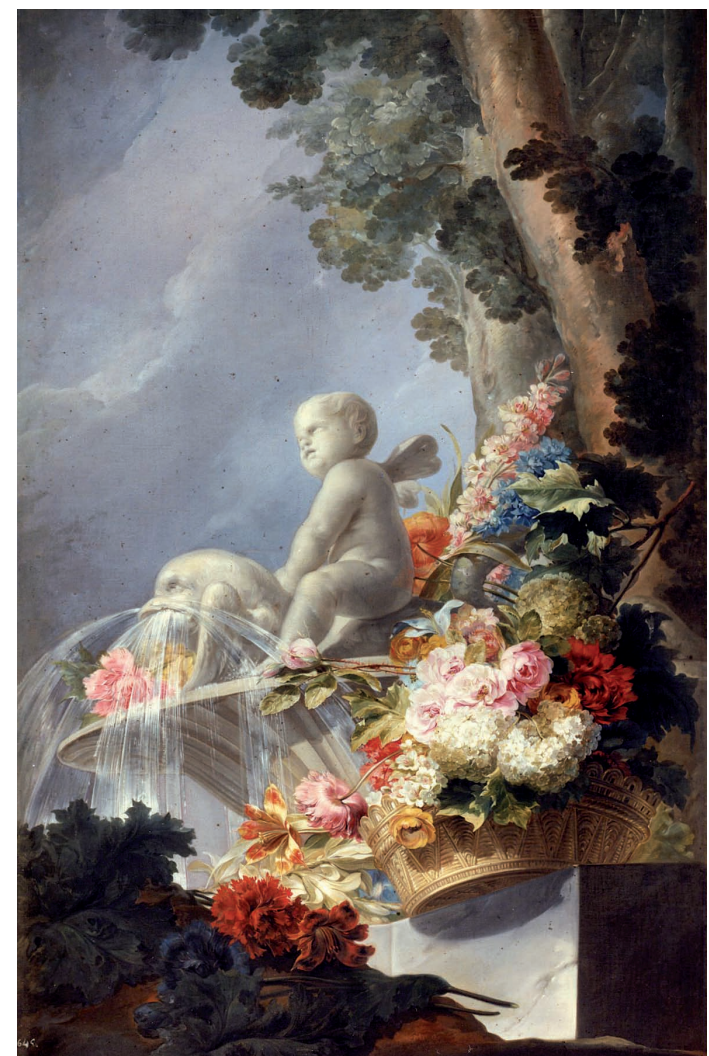

Fig. 6. Miguel Parra, Cesto de flores en un jardin, 1822. San Lorenzo de El Escorial, Casita del Príncipe.

trabajos para la decoración de los Reales Sitios. Entre las obras enviadas por el pintor valenciano se encuentran varios retratos, cuadros religiosos y, lo que nos interesa ahora, pinturas de bodegones y floreros. Gracias a la documentación conservada en el Archivo del Palacio Real de Madrid, se han podido identificar algunos de los cuadros de flores que Parra enviaba regularmente a Fernando VII y posteriormente a la reina María Cristina ${ }^{28}$. Actualmente sólo se conocen seis de estas obras, de extraordinaria calidad, que marcan un punto de inflexión en la producción del artista valenciano. En el zaguán de entrada de la Casita del Príncipe de El Escorial pueden hoy contemplarse la serie de cuatro lienzos realizados en $1822^{29}$. Detengámonos al menos en dos de ellos.

El primer cuadro, un Florero en un jardín (fig. 5) está protagonizado por un gran jarrón de estilo clásico ocupado en su gran mayoría por ramas de bolas de nieve, cortadas y dispuestas en

${ }^{28}$ Esta documentación, que corresponde al Expediente personal de Miguel Parra Caja 791/Exp. 51 se dio a conocer en la tesis doctoral de Alba PAGÁn, 2003: vol. IV.

${ }^{29}$ La serie está compuesta por un Florero en un jardín, que figura en el inventario de Patrimonio Nacional con el número 10032656; otro lienzo del mismo título ( $\mathrm{n}^{\circ}$ de inventario 10032655); un Florero y cesto de flores en un jardín $\left(\mathrm{n}^{\mathrm{o}}\right.$ 10032648), todos ellos de $156 \times 101 \mathrm{~cm}$ y un Cesto de flores en un jardín ( $\left.\mathrm{n}^{\mathrm{o}} 10032649\right)$, de $196 \times 161 \mathrm{~cm}$. Esta serie de reproduce en el estudio de López Terrada, 2001: 344-347. Sobre estas obras, ver también Alba Pagán, 2001: 776-779. 
precario equilibrio, con sus correspondientes hojas, además de otras especies como amapolas, tanto simples como de flor doble, que aportan toques rojos y rosas, y pequeñas arañuelas de color azul. Este jarrón se levanta sobre una fuente de mármol de perfiles geométricos que tiene como surtidor un rostro masculino coronado de laurel. Tras este primer plano marmóreo más claro y frontal, la estructura de la fuente se prolonga oscurecida en ambas direcciones, adquiriendo profundidad hacia la derecha. Este marco "clásico" y un tanto frío se ve invadido por dos grandes grupos florales. El inferior, compuesto por ejemplares cortados de rosas, adormideras, espuelas de caballero y francesillas principalmente, ocupa en su amplio colorido todo el extremo inferior, que se encuentra intensamente iluminado y que se prolonga, ya en un primer plano, sobre la basa de la fuente. El segundo grupo de flores, situado a los pies del jarrón, mantiene el mismo criterio de exposición de ejemplares cortados y aparentemente apilados con descuido, entre los que sobresale, sobre un trío de claveles, una hermosa azucena roja (Lilium bulbiferum L.). Toda esta composición, inscrita en un paisaje de celaje despejado, como el resto de la serie, se compensa con una planta de pita dispuesta en la parte central derecha.

En el segundo de los lienzos de esta serie (fig. 6), un Cesto de flores en un jardín, Parra ha conseguido un mayor efecto decorativo. El repertorio botánico habitual se desborda en este caso de un cesto apoyado sobre un plinto, prolongándose hasta el suelo de tierra por el extremo izquierdo inferior y enlazándose con los árboles que ocupan buena parte del margen derecho. En este encuadre vegetal se inserta una fuente de cuerpo avenerado con un niño alado sentado sobre un delfín. Su delicada resolución técnica rivaliza con la veracidad y la luz del arreglo floral. El resto de la serie, de características muy similares, presenta la misma perfección técnica y complejidad compositiva que los cuadros descritos. Puede decirse que formalmente nos encontramos ante una adaptación deudora de las enseñazas de Benito Espinós, pero en la que resulta igualmente evidente el conocimiento de los modelos de los grandes maestros de flores franceses como PierreJoseph Redouté (1759-1840) y, sobre todo, de las obras de los integrantes de la Escuela de Lyon, como Antoine Berjon (1754-1843) o Jean-François Bony (1754-1825), que habían asimilado la destreza técnica de los artistas flamencos y holandeses del siglo XVII. Gracias a la impecable precisión como dibujante que Parra adquirió a partir de las enseñanzas de Vicente López, el artista valenciano materializa en esta obra el mismo rasgo distintivo que caracteriza la producción de estos últimos pintores franceses: "el bello artificio" y la "difícil combinación de llamativos arreglos florales con un melancólico sentimentalismo" 30 .

En la Casita del Príncipe de El Escorial se conserva además un Jarrón de flores ante una vista del Palacio Real de Valencia, que como ha puesto de manifiesto Alba Pagán debió realizarse en 1839 por encargo directo de María Cristina ${ }^{31}$. Gracias a la documentación conservada en el Archivo del Palacio Real de Madrid, sabemos que la reina apreciaba especialmente este tipo de composiciones de flores y tuvo la intención de crear una colección de cuadros de Miguel Parra ${ }^{32}$. Lamentablemente, en la actualidad esta colección se haya dispersa y sólo permanece un último cuadro

\footnotetext{
${ }^{30}$ Hardouin; Grafe, 1989: 26.

${ }^{31}$ La obra mide $90 \times 75 \mathrm{~cm}$ y figura en el inventario de Patrimonio Nacional con el número 10032718. Como indica Alba PagÁn, 2001: 776, nota 39, en un Memorial de 1841 de la Intendencia General de la Real Casa y Patrimonio, el "Bayle general" recoge que: "en 30 de octubre de 1838 avisó el Bayle de Valencia que el propio Parra había remitido á su hermano político D. Vicente López dos pinturas correspondientes a aquel año para S. M., y el Don Vicente López [... ] avisó que los había entregado á la soberana, y había quedado muy satisfecha, manifestándole su Real voluntad de que en los cuadros que Parra pintase en el año siguiente introdujese en uno de ellos la vista del Real Palacio del Real". Archivo de Palacio Real, Expediente Personal. Miguel Parra. Caja 791/14.

32 Según recoge Alba Pagán, 2001, nota 44, en la Memoria de 1844 levantada por la Intendencia sobre las obras entregadas por Parra consta que: "en el año anterior remitió el mismo Parra dos cuadros por conducto de D. Vicente López, quien los presentó á esta intendencia, y se mandó al Alcayde Principal de Palacio en 24 de Febrero de 1841 que los
} 
en Patrimonio Nacional. Se trata de una Cesta de flores en un jardín, que hoy se encuentra en el Palacio de San Ildefonso ${ }^{33}$.

Como puede comprobarse, el estudio de la pintura de flores de Miguel Parra no puede desligarse de su brillante trayectoria académica y profesional, ni de su intensa y variada actividad pictórica, aspectos que explican que nos encontremos ante uno de los artistas valencianos más relevantes de la primera mitad del siglo XIX ${ }^{34}$. Desde Valencia, Parra trabajó además como retratista, pintor religioso y diseñador de decoraciones y monumentos efímeros. En cuanto a su trayectoria en la Academia de Bellas Artes, ocupó la Dirección de la Clase de Pintura en 1821, el cargo de Tasador oficial de Pinturas y, desde 1823 hasta 1827, la Dirección General. Fue también el encargado de la formación del Museo de la Academia con las obras procedentes de la desamortización y formó parte de las principales asociaciones artísticas de la ciudad. Desde este momento hasta su muerte, que se produjo en Madrid en 1846 cuando acompañaba a su hijo José Felipe a la Corte, transcurrió una de las etapas más fecundas de su carrera que acabó de confirmar su trascendencia en el panorama pictórico decimonónico.

No obstante, aunque Parra cultivó muchos géneros pictóricos, su fama se debió principalmente a sus composiciones florales. Las dos obras que ahora se dan a conocer demuestran la versatilidad de este artista como pintor de flores.

La primera de ellas es un óleo sobre tabla de $50,5 \mathrm{~cm}$ de alto por 37 de ancho y pertenece a la colección Naseiro (fig. 7). No está fechada, pero está firmada en un zarcillo, como una prolongación de una hoja de vid. Este tipo de firma, que parece una especie de juego y que también utilizará su hijo José Felipe Parra ${ }^{35}$, figura en otras composiciones del artista como sucede, por ejemplo, en las Flores y pájaro en un paisaje que se conserva en el Museo de Bellas Artes de Valencia (fig. $8)^{36}$. Esta última, donada por el propio artista a la Academia de San Carlos, es una obra singular, realizada al óleo sobre un grueso cristal, con la que presenta innegables similitudes. En ambos casos, la liberación de las directrices académicas más rígidas impuestas en el estudio de flores se hace evidente.

Por otra parte, frente al carácter de "ilustrador botánico" que caracteriza buena parte de la producción de Parra, vemos aquí otra manera de enfrentarse a la representación floral mediante una

recogiera y uniese a las remesas de años anteriores para formar una colección del Artista Dn. Miguel Parra, y como el mencionado Alcayde manifestase que además de los cuadros que se le entregaron en esta Intendencia, había recibido otros del propio autor por orden de S. M. La Reyna Gobernadora, le había sido necesario construir cuatro marcos, cuyo importe era de 12 r." Archivo de Palacio Real. Expediente personal de Miguel Parra. Caja 791/14.

${ }^{33}$ Este lienzo mide $92,5 \times 71 \mathrm{~cm}$ y figura en el inventario de Patrimonio Nacional con el número 10041057. Tampoco se conoce el paradero de la pareja de floreros que estuvo en el Museo del Prado hasta 1861. Procedían de los bienes artísticos desamortizados por Mendizábal que fueron reunidos en el convento de la Trinidad y que posteriormente se unieron a las colecciones reales. Gracias a la información proporcionada en el Inventario del Museo de 1854, sabemos que estos lienzos tenían un tamaño aproximado, $136 \times 90 \mathrm{~cm}$, y una composición similar a las obras de El Escorial. En el Inventario de 1854, el primero de ellos se describe como "un florero en el fondo de un jardín con rosas, mundos, claveles y amapolas y otras varias con una cascada a la izquierda del espectador". El otro era "un florero en el fondo de un jardín, en el fondo se [ve] un canastillo colgado de la rama de un árbol con claveles, mundos, amapolas y otras flores- en la parte baja gran porción de flor".

${ }^{34}$ Entre los autores que se han ocupado de la obra de Miguel Parra pueden citarse a: Ossorio y Bernard, 1868-1869: 515-516. Boix, 1877: 52. Alcahalí, 1897: 234-235. Cavestany, 1936-1949: 57 y 103. Aldana Fernández, 1970a: 190195; Aldana Fernández, 1970b: 263-264. Pérez Sánchez, 1983: 214. Vilapana Zurita, 1989, vol. I: 318-318. Borrego Pitarch, 1991: 317-319; Gil Salinas, 1992: 41 y 121-133. Pérez SÁnchez, 1996: 105-111. López Terrada, 2001: 241243. Alba Pagán, 2003: 1725-1903. Benito Doménech; Gómez Frechina, 2006: vol. I, 175-179. Portús, 2006: 14-21. LUNA, 2008: 164.

${ }^{35}$ OÑa IRRIBARREn, 1944: 65 y 69

${ }^{36}$ Este óleo tiene además unas dimensiones similares, ya que mide $53 \times 41 \mathrm{~cm}$. Museo de Bellas Artes de Valencia ( $\mathrm{n}^{\mathrm{o}}$ de inventario 2001). 


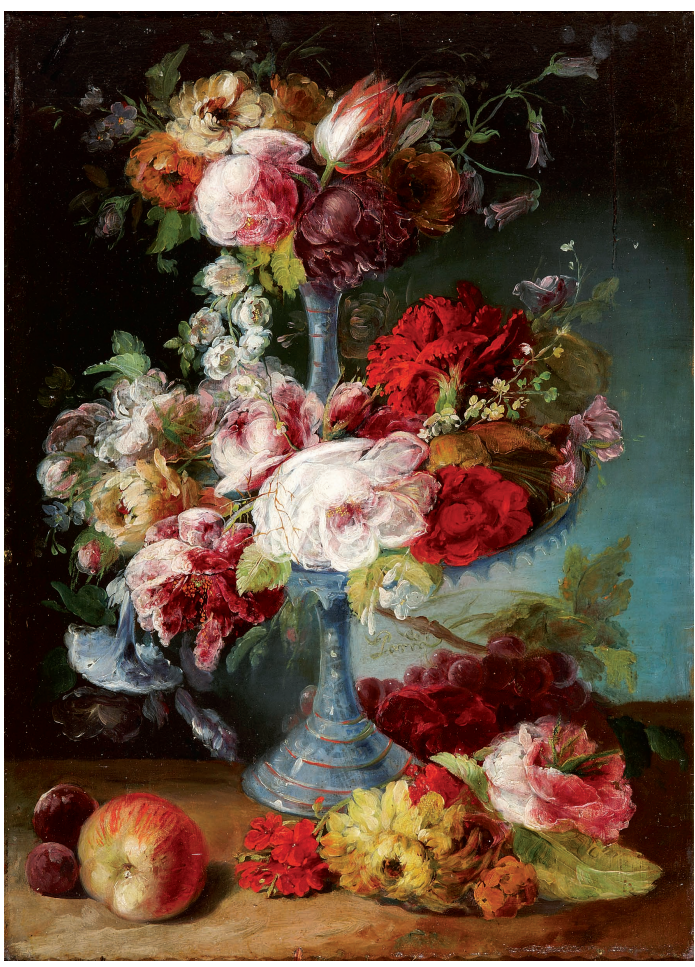

Fig. 7. Miguel Parra, Florero. Colección Naseiro.

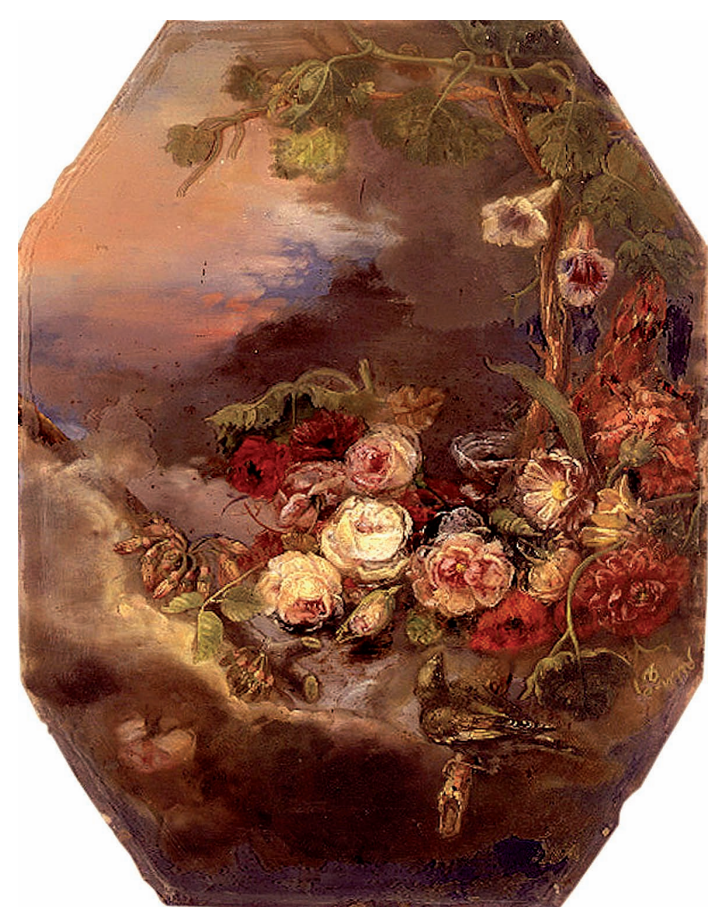

Fig. 8. Miguel Parra, Flores y pájaro en un paisaje, Museo de Bellas Artes de Valencia.

pincelada más suelta y empastada y unos contornos menos definidos. Existe, finalmente, un último elemento común en ambas obras: se trata de una rosa sin el tallo dispuesta hacia abajo. En el cuadro de las Flores y pájaro en un paisaje se sitúa de forma un tanto inverosímil, casi flotando, en el ángulo inferior izquierdo, mientras que en la tabla de la colección particular se representa de forma mucho más nítida en el ángulo inferior derecho. La presencia de este mismo elemento botánico, procedente de un estudio previo tomado del natural, junto a las similitudes antes anotadas, podría considerarse un argumento más para presumir la posible proximidad cronológica de estas pinturas.

Sin embargo, desde el punto de compositivo, la tabla de la colección Naseiro se inscribe, en principio, en el tipo más habitual desarrollado por los integrantes de la Escuela valenciana: los floreros en sentido estricto ${ }^{37}$. Éstos suelen disponerse sobre un fondo neutro y bases pétreas, mientras que las distintas especies vegetales se presentan en floreros que varían desde los más sencillos recipientes de cristal o barro hasta los jarrones más elaborados de estilo neoclásico. En el caso concreto de esta obra de Parra, su composición general recuerda la producción más madura de su maestro Benito Espinós y la desarrollada por otros pintores de la Escuela valenciana de una generación anterior a la suya, especialmente, la de Juan Bautista Romero (1756-1804) ${ }^{38}$.

En el cuadro de Parra, los contenedores habituales se han sustituido por un peculiar recipiente a medio camino entre jarrón y frutero, que tiene los bordes dentados y un reflejo que le otorga una

${ }^{37}$ LÓPEZ TERRADA, 2001: 157-162

${ }^{38}$ López TERRADA, 2001: 251-253, Los floreros a los que hago referencia se reproducen en la obra de SÁnCHEZ LóPEZ, 2008: 547-554.

Arch. esp. arte, LXXXVI, 342, ABRIL-JUNIO 2013, 123-142, ISSN: 0004-0428 
apariencia metálica. Las referencias espaciales son en este caso mínimas, pues se reducen a una base de color amarronado que se va oscureciendo progresivamente para conseguir un efecto de profundidad. Como es habitual, el intenso cromatismo de los elementos vegetales representados destaca sobre un fondo oscuro y neutro, que únicamente se ilumina en este caso en el extremo central derecho para permitir apreciar un racimo de uvas (Vitis vinifera L.) con la firma ya mencionada del artista y una rosa apenas esbozada. Sobre la mesa, ocupando el ángulo inferior izquierdo, se representan un tanto aisladas otras frutas: dos prunas (Prunus domestica L.) y una manzana (Pyrus malus L.), mientras que la base del jarrón se oculta parcialmente con pequeñas flores rojas de geranio (Pelargonium odoratissimum L.), un narciso doble (Narcissus $x$ incomparabilis Mill.) y la rosa sin tallo (Rosa $x$ damascena Mill.).

En cuanto al arreglo floral, si comenzamos la identificación botánica por la parte superior, podemos distinguir cómo la parte central está ocupada por la llamada rosa de cien hojas (Rosa centifolia L.) que empieza a abrir sus pétalos, junto a un tulipán (Tulipa sp.) y una flor morada que podría corresponder a un cultivar de dalia (Dahlia pinnata Cav. $)^{39}$. A ambos lados se disponen cultivares de anémonas (Anemone coronaria L.), mientras que los extremos se completan con especies de color más apagado que equilibran el grupo, de manera que éste puede inscribirse en un triángulo invertido. Las delicadas flores azules del lino (Linum perenne L.) se disponen a la izquierda, mientras que la derecha se reserva para los farolillos (Campanula medium L.). La combinación de especies silvestres con otras muy de moda en los jardines de la época, como sucede, por ejemplo, con las anémonas y con novedades botánicas, como las dalias, es una característica típica de este tipo de obras desde el siglo XVII.

Este grupo superior comunica con el central mediante una rama de flores dobles de manzano (Pyrus malus L.) que dirige nuestra vista a la gran rosa blanca (Rosa $x$ alba L.) del centro de la composición. A diferencia de la lozanía que caracteriza las especies vegetales de la gran mayoría de los cuadros de Parra, en esta tabla muchas de las flores parecen estar a punto de marchitarse. Este hecho se hace especialmente evidente en el ejemplar de rosal castellano (Rosa gallica L.), casi deshecho, que se sitúa muy próximo a la rosa blanca y en las campanillas (Ipomoea tricolor Cav.) que le acompañan y dan la sensación de estar a punto de caer del florero. Sobre ellas, y completando el grupo central se representan, a la izquierda, flores de lino y distintas especies de rosas en diferentes estados de desarrollo. Entre ellas pueden distinguirse una rosa de Alejandría (Rosa $x$ damascena Mill.) con sus correspondientes capullos y una rosa amarilla (variedad de Rosa hemisphaerica Herrm.). Siguiendo una distribución en diagonal, en la parte que queda a la derecha de la rosa blanca, destaca un exuberante clavel rojo (Dianthus caryophyllus L.), flores simples de malva real (Alcea rosea L.) y una pequeña rama florida de jazmín amarillo o silvestre (Jasminum fruticans L.). Bajo lo que parece una rosa de un intenso color rojo, Parra ha incluido un jazmín común (Jasminum officinale L.), casi transparente, en primer plano, recurso mediante el cual se indica la profundidad del recipiente.

La segunda composición de flores de Miguel Parra inédita hasta el momento pertenece a una colección particular valenciana (fig. 9). Se trata de un óleo sobre lienzo que mide $105 \mathrm{~cm}$ de alto por 75 de ancho, superando así el tamaño de muchos de los lienzos conocidos de la Escuela valenciana de Flores. Está firmado y fechado en la base de la estructura metálica que cubre la fuente, en el extremo inferior derecho, donde puede leerse con claridad: "Miguel Parra, año 1843". Se trata, por tanto, de un trabajo de madurez pensado para satisfacer el gusto de la clientela burguesa a la que iba destinado.

Desde el punto de vista compositivo, el lienzo recuerda a los trabajos que Parra realizó para Fernando VII hacia 1822, concretamente a la serie de cuatro óleos que hoy se disponen como so-

${ }^{39}$ La ausencia de hojas, salvo la que corresponde a la rosa, de un verde intenso, no permite precisar más la identificación.

Arch. esp. arte, LXXXVI, 342, ABRIL-JUNIO 2013, 123-142, ISSN: 0004-0428 


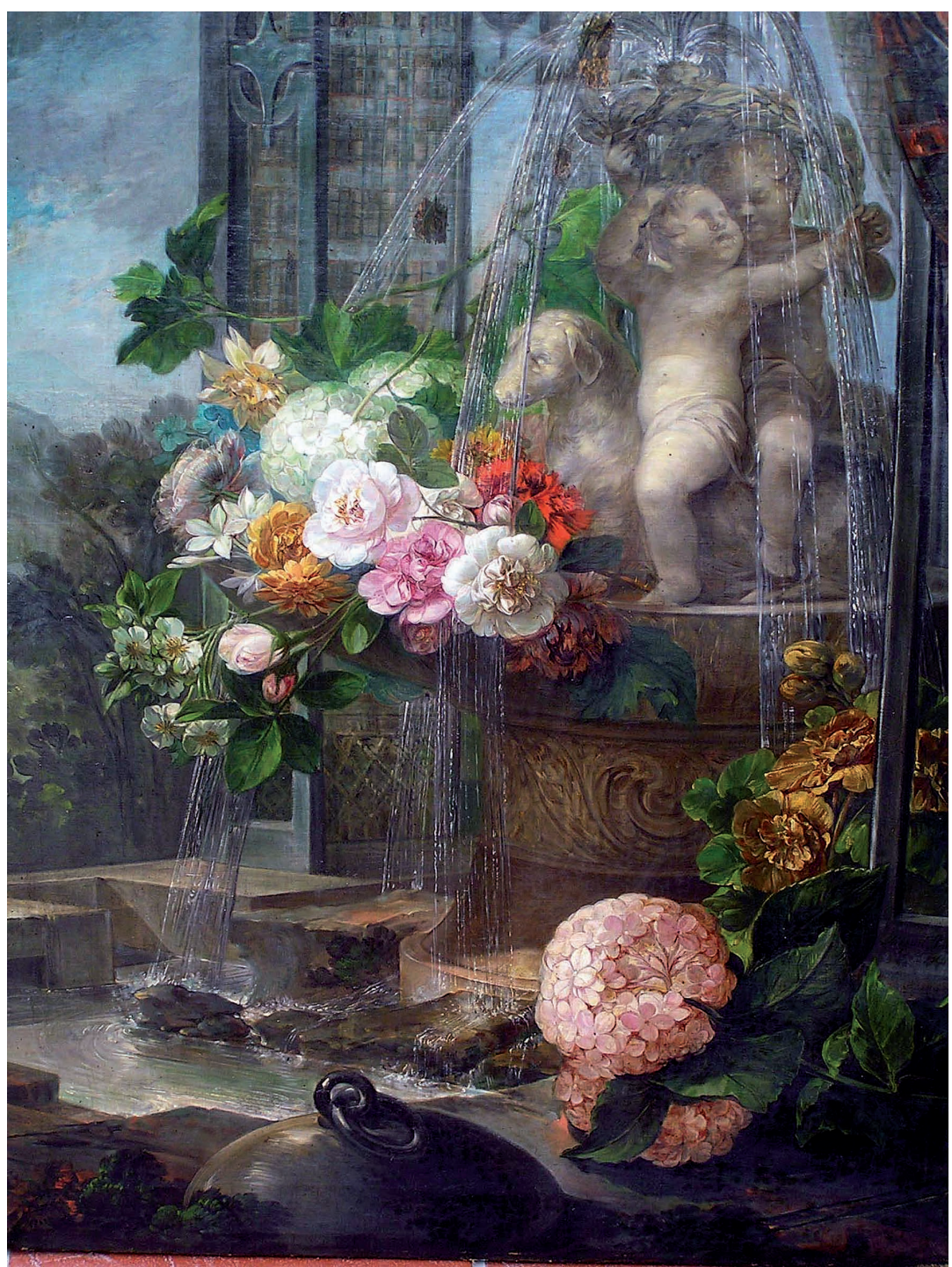

Fig. 9. Miguel Parra, Flores en un jardín. Colección particular, Valencia.

brepuertas en el zaguán de entrada de la Casita de El Príncipe de Escorial. Al igual que en estas obras, la compleja fuente y las flores que las protagonizan se sitúan en un jardín que se abre en el ángulo superior izquierdo mediante la insinuación de unos árboles y un paisaje montañoso.

En el caso concreto de esta obra, el virtuosismo técnico de Parra no se demuestra tanto en el desigual dibujo de los putti que coronan la fuente, sino en su capacidad para representar las diferentes calidades de los elementos vegetales, lo que permite que puedan ser identificados con precisión. El grupo central, donde se concentra la luz y la riqueza del color, corresponde a su repertorio más habitual. La disposición de las ramas de características hojas trilobuladas y flores blancas del viburno o bola de nieve (Viburno opulus L.) marcan la dirección oblicua de una agrupación de rosas blancas (Rosa x alba L.), rosas rosas (Rosa gallica L. y Rosa provinicialis Mill.) y una 
amarilla (variedad de flor doble de Rosa eglanteria L.). Estas rosas se rodean de claveles (Dianthus caryophyllus L.) por la parte inferior y se coronan con un ejemplar de narciso doble (Narcissus $x$ incomparabilis Mill.). La profundidad se consigue mediante la disposición del ramillete de jazmín azul (Plumbago auriculata Lam.), ante el cual se representan en orden descendente una adormidera (Papaver somniferum L.), un grupo de flores un tanto rígidas de jazmín español (Jasminum grandiflorum (L.) Kabiski) y una dalia amarilla doble (Dahlia coccinea Cav.). Este arreglo finaliza con capullos de rosas rosas y una rama de cerezo florecido (Prunus avium L.) que desborda la basa de la fuente. El ángulo inferior derecho del lienzo queda reservado para una planta de malva real de flores doradas (Alcea rosea L.), que continúa la línea oblicua del ramo central, y un hermoso ejemplar de hortensia de color rosa (Hydrangea macrophylla) fuertemente iluminado y dispuesto en un primerísimo plano. Esta situación no es casual, pues en muchas de sus composiciones florales, Parra reserva los primeros planos para destacar las novedades botánicas de la época. Es el caso de la hortensia, que no fue introducida en la jardinería europea hasta el siglo XVIII ${ }^{40}$.

Las marcadas diferencias que presentan estas dos obras de Parra podrían llevarnos a pensar que nos encontramos ante una evolución de su producción pictórica. Sin embargo, sin descartar totalmente este hecho, parece más oportuno considerar estas discrepancias como dos procedimientos o técnicas distintas utilizadas por el artista a la hora de abordar la representación floral: una de factura más rápida y de contornos más imprecisos, reservada para obras de pequeño formato, $\mathrm{y}$ otra, donde predomina el dibujo y el deseo de ilusionismo con resultados altamente decorativos. A este último estilo, minucioso y detallista, corresponden no sólo las obras que realizó para los monarcas, sino también las dos espectaculares composiciones de la colección Naseiro que fueron adquiridas por el Museo del Prado en 2006: el Florero sobre una silla y el Cesto de flores con vista de Palacio, firmadas en $1844^{41}$. Este tipo de lienzos, que constituyen la producción más admirada de Parra, fue la que le valió el sobrenombre del "Don Vicente López de las flores" ideado por Elías Tormo en 1932, que hizo fortuna entre los autores posteriores que se han acercado a la figura del artista.

No obstante, gracias al conocimiento de los dos floreros procedes de la colección Orts-Bosch incorporados a los fondos del Museo de Bellas de Valencia, sabemos ahora que el pintor continuó cultivando estas dos formas de representación hasta el final de su vida. La primera composición floral, realizada en 1845, puede inscribirse en su producción más característica (fig. 10). Está protagonizada por un gran cántaro lleno de espléndidas flores situado en un jardín con una fuente. La segunda (fig. 11) es una tabla de dimensiones más reducidas que está firmada y fechada en 1846, el año de su muerte ${ }^{42}$. Se trata de una obra que muestra muchas similitudes técnicas y compositivas con el lienzo inédito de la colección Naseiro, aunque su resolución es mucho más sencilla.

En cualquier caso, sea cual sea la técnica empleada por Miguel Parra, lo que resulta innegable es que su talento le convirtió en uno de los pintores de flores más reconocidos de su época. Así lo muestran las palabras que le dirigió Vicente Boix en la necrológica que le dedicó el 7 de febrero de 1847, tan sólo unos meses después de su muerte, en el Fénix, una de las revistas que gozó de mayor relevancia en la vida cultural valenciana ${ }^{43}$. Tras repasar su brillante trayectoria profesional y mencionar algunas de sus composiciones artísticas más relevantes señala:

${ }^{40}$ Como explica ElLIot, 2001: 277-278: "Las primeras hortensias que llegaron a Europa en el siglo XVIII eran especies americanas, pero fueron rápidamente eclipsadas por variedades chinas y japonesas (...) Su clasificación fue al principio poco segura, y fueron etiquetadas como viburnos, saúcos y hortensias (todavía su nombre vernáculo en muchas partes de Europa) antes de que su parentesco con las especies americanas fuera percibido. Hydrangea hortensia siguió siendo su nombre durante mucho tiempo, antes de pasar a ser H. Macrophylla".

${ }^{41}$ Esta pareja de lienzos, que miden $120 \times 92 \mathrm{~cm}$, se analizan en el trabajo de LunA, 2008: 148-151.

${ }^{42}$ El Cántaro de flores junto a una fuente mide $76,5 \times 52,7 \mathrm{~cm}$, mientras que el Florero tiene unas dimensiones de $38,8 \times 29,3 \mathrm{~cm}$. Museo de Bellas Artes de Valencia. Inventario General 70/2004 y 184/2004. Ambas obras de reproducen y analizan en el catálogo de Benito Doménech; Gómez Frechina, 2006: 176-179.

43 Alba Pagán, 2007: 22. 


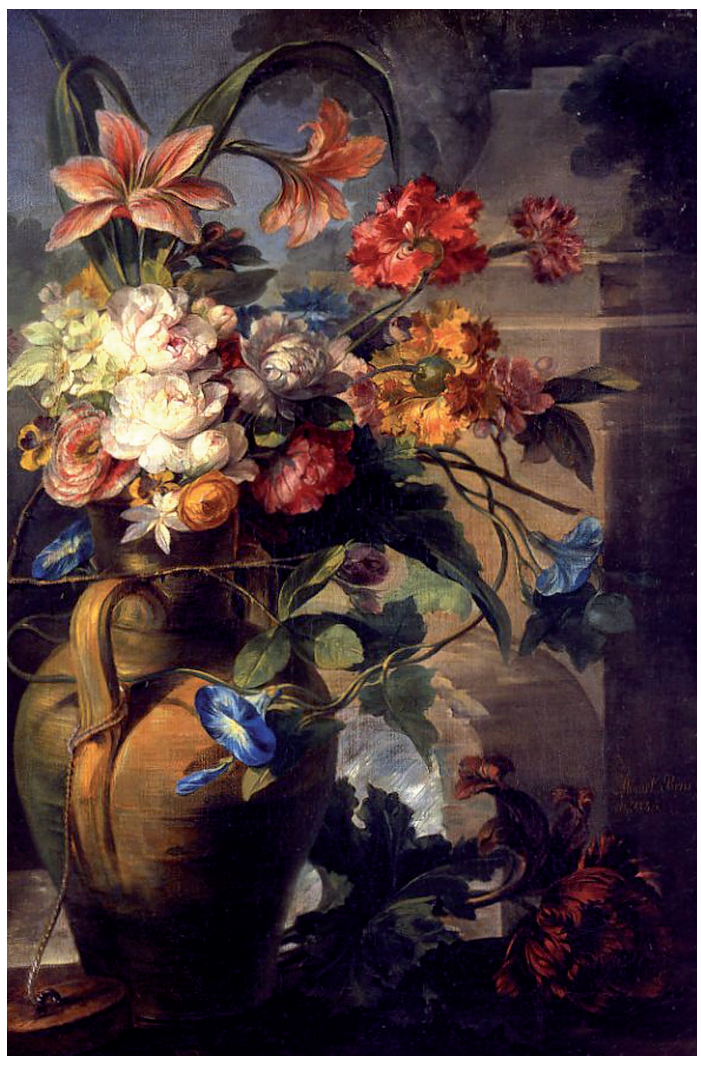

Fig. 10. Miguel Parra, Cántaro de flores junto a una fuente, 1845. Museo de Bellas Artes de Valencia.

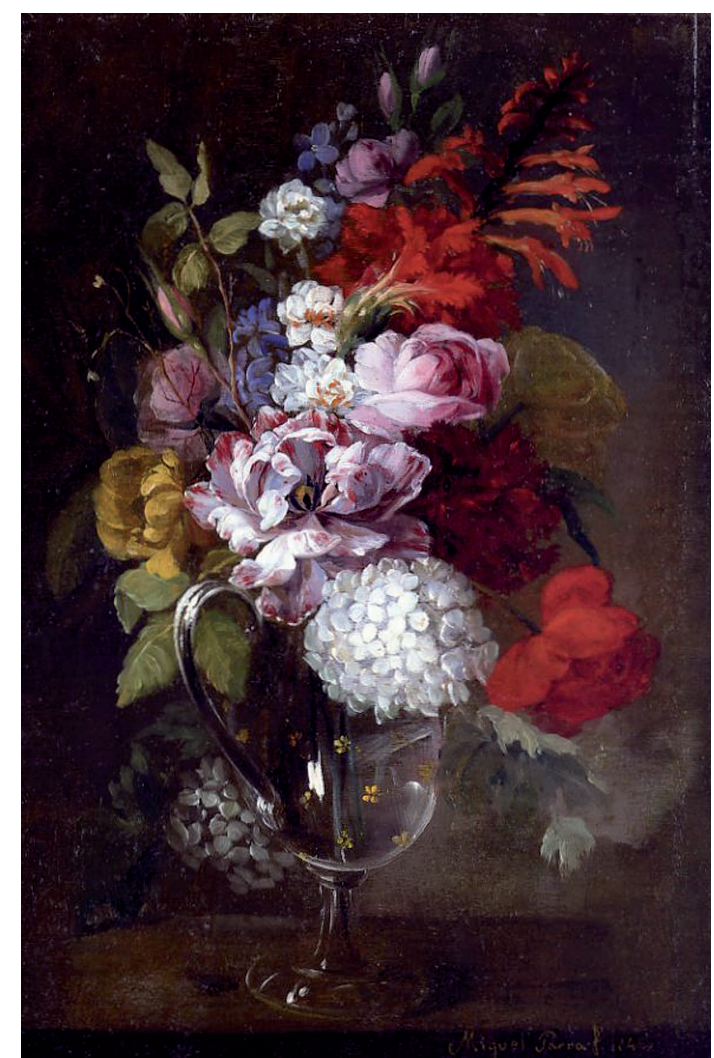

Fig. 11. Miguel Parra, Florero, 1846. Museo de Bellas Artes de Valencia.

"Si fue escelente (sic.) en esta clase de obras lo fue mucho más en el ramo de las flores y en el paisage y adorno, excediendo no sólo á su maestro el célebre Espinós, sino colocándose en una altura á que ninguno de sus contemporáneos ha podido llegar. El genio de Parra supo crearse en este ramo un nombre tan esclarecido que sin duda podremos asegurar ser el único que en nuestros tiempos ha obtenido con justicia esa indisputable celebridad, no sólo en España, sino también en el estranjero. Nótase sobre todo, en las obras suyas de esta clase, un gusto tan delicado en el dibujo, tal frescura y transparencia en las hojas, y tanta elegancia y armonía en sus composiciones bellísimas, fantásticas y poéticas, que la naturaleza parece embellecida bajo su pincel, destinado por un misterioso privilegio á reproducir en pequeños espacios toda la gala, el esplendor y la verdad de la creación lozana y deliciosa. Inagotable en este género ha dejado Parra la abundante y rica colección de floreros que adornan dignamente algunas habitaciones del regio alcázar de Madrid, con admiración de los naturales y estrangeros. Nosotros mismos le hemos podido observar en su avanzada edad entregado con una delicia infinita á estas obras, en las que se respira todo el gusto, soltura y encanto de la más brillante juventud, y la perfección y acabamiento de la última edad del genio" ${ }^{44}$.

${ }^{44}$ Borx, “Artistas valencianos”, El Fénix, no 71, 7-II-1847: 229. 


\section{BIBLIOGRAFÍA}

Alba Pagán, Ester, "La pintura y los pintores valencianos en las "Casitas" del Real Sitio de San Lorenzo del Escorial: Mariano Salvador Maella, Benito Espinós, Miguel Parra, José López Enguídanos y Mariano Sánchez", en Campos, Francisco Javier (coordinador), El Monasterio del Escorial y la pintura, Servicio de Publicaciones del Real Colegio Universitario Escorial-María Cristina, 2001, pp. 757-784.

Alba Pagán, Ester, La Pintura y los pintores valencianos durante la Guerra de la Independencia y el reinado de Fernando VII (1808-1833), 4 vols., Valencia, Tesis doctoral de la Universitat de València, 2003.

Alba Pagán, Ester, Pintura y crítica de Arte en Valencia (1790-1868), Valencia, Universitat de València, 2007.

Alcahalí, Barón de (José Ruiz de Lihori), Diccionario biográfico de artistas valencianos, Valencia, Federico Doménech, 1897.

Aldana Fernández, Salvador, Pintores valencianos de flores (1766-1866), Valencia, Instituto Alfonso el Magnánimo, 1970a.

Aldana Fernández, Salvador, Guía abreviada de artistas valencianos, Valencia, Ayuntamiento de Valencia, 1970b.

Benito Doménech, Fernanado; Gómez Frechina, José, La Col.lecció Orts-Bosch al Museu de Belles Arts de València, 2 vols., Valencia, Generalitat Valenciana, 2006.

Boix, Vicente, Noticia de los artistas valencianos del siglo XIX, Valencia, Imprenta de Manuel Alufre, 1877.

Borrego Pitarch, Vicente, "Parra Abril, Miguel", en Arnáiz, José Manuel (dir.), Cien años de pintura en España y Portugal (1830-1930), Madrid, Antiquaria, vol. VII, pp. 317-319.

Boutelou, Claudio y Esteban, Tratado de las flores: en que se explica el método de cultivar las que sirven para adorno de los jardines..., Madrid, en la Imprenta Villalpando, 1804. Edición facsímil de París-Valencia, 1993.

Cavestany, Julio, Floreros y Bodegones en la pintura española, Madrid, Sociedad Española de Amigos del Arte, 1936-1940.

Espinós Díaz, Adela, "Dibujos de flores aplicados al tejido en la Colección de la Real Academia de Bellas Artes de San Carlos", en Franch Benavent, Ricardo et al., Arte de la seda en la Valencia del siglo XVIII, cat. exp., Valencia, Fundación Bancaja, 1997, pp. 81-105.

Elliott, Brent, Flora. Historia ilustrada de las flores de jardín, London, Cartago, 2001.

Gil Salinas, Rafael, El món de Goya i López en el Museu Sant Pius V, Valencia, cat. exp., Valencia, Generalitat Valenciana y Museu Sant Pius V, 1992.

Hardouin-Fugier, Elisabeth; Grafe, Etienne, French Flower Painters of the 19th Century. A Dictionary, London, Philip Wilson Publishers, 1989.

León Tello, Francisco José; Sanz Sanz, María Virginia, La estética académica española en el siglo XVIII: Real Academia de Bellas Artes de San Carlos de Valencia, Valencia, Institución Alfonso el Magnánimo, 1979.

López Terrada, María José, "El contexto histórico: la Escuela valenciana de Flores y la Botánica”, en Franch Benavent, Ricardo et al., Arte de la seda en la Valencia del siglo XVIII, cat. exp. Valencia, Fundación Bancaja, 1997, pp. 49-61.

López Terrada, María José, Tradición y cambio en la pintura valenciana de flores 1600-1850, Valencia, Ayuntamiento de Valencia, 2001.

López Terrada, María José, "La pervivencia del lenguaje alegórico en la Academia valenciana: La Representación de las Bellas Artes (ca. 1801), de Miguel Parra", en Actas del XV Congreso Nacional de Historia del Arte, Palma de Mallorca, 2008 Adenda, pp. 1-10.

López Terrada, María José; Alba Pagán, Ester, "La imagen victoriosa de Fernando VII. Las entradas triunfales del pintor Miguel Parra (1780-1846)", en Actas de las XII Jornadas Nacional de Historia Militar, Sevilla, 2004, vol. II, pp. 607-622.

López Terrada, María José; Alba Pagán, Ester, "La entrada triunfal de Fernando VII en Zaragoza, un lienzo conmemorativo de Miguel Parra (1780-1846)", Boletín del Museo e Instituto Camón Aznar, CI, 2008, pp. 143-170.

Luna, Juan J. , El bodegón español en el Prado. De Van der Hamen a Goya, Madrid, Museo del Prado, 2008.

Martínez, Francisco, Introducción al conocimiento de las Bellas Artes o Diccionario Manual de Pintura, Escultura, Arquitectura, Grabado, \&. Con la descripción de sus mas principales asuntos: Dispuesto y re-

Arch. esp. arte, LXXXVI, 342, ABRIL-JUNIO 2013, 123-142, ISSN: 0004-0428 
cogido de varios Autores, asi Nacionales como Estrangeros (sic.), para uso de la Juventud Española, Madrid, por la Viuda de Escribano, 1788. Edición facsímil de la Real Academia Española y Colegio Oficial de Aparejadores y Arquitectos Técnicos, Málaga, 1989.

Navarrete Martínez, Esperanza, La Academia de Bellas Artes de San Fernando y la pintura en la primera mitad del siglo XIX, Madrid, Fundación Universitaria Española, 1999.

Oña Iribarren, Gelasio, 165 firmas de pintores tomadas de cuadros de flores y bodegones, Madrid, Sociedad Española de Amigos del Arte, 1944.

Ossorio y Bernard, Manuel, Galería biográfica de artistas españoles del siglo XIX, Madrid, Imprenta de Moreno y Rojas, 1868-1869.

Pérez Sánchez, Alfonso Emilio, Pintura española de Bodegones y Floreros. De 1600 a Goya, Madrid, Ministerio de Cultura, 1983.

Pérez Sánchez, Alfonso Emilio, Naturalezas muertas y flores del Museo de Bellas Artes de Valencia, cat. exp. Valencia, Museo de Bellas Artes de Valencia, 1996

Pérez Sánchez, Alfonso Emilio, "La pintura valenciana de flores”, en Franch Benavent, Ricardo et al., Arte de la seda en la Valencia del siglo XVIII, Valencia, Fundación Bancaja, 1997, pp. 31-47.

Portús, Javier, Lo fingido verdadero. Bodegones españoles de la colección Naseiro adquiridos para el Prado, cat. exp., Madrid, Museo Nacional del Prado, 2006.

Rodríguez García, Santiago, El arte de las sedas valencianas en el siglo XVIII, Valencia, Institución Alfonso el Magnánimo, 1959.

Sánchez López, Andrés, La pintura de bodegones y floreros en España en el siglo XVIII, Madrid, Fundación Arte Hispánico, 2008.

Vilaplana Zurita, David, "Neoclasicismo, Academicismo, Romanticismo. La Pintura”, en Aguilera Cerni, Vicente (director), Historia del Arte Valenciano, Valencia, Consorci d'Editors Valencians, 1989, vol. IV, pp. 299-325.

Fecha de recepción: 12-VI-2012

Fecha de aceptación: 12-XI-2012

Arch. esp. arte, LXXXVI, 342, ABRIL-JUNIO 2013, 123-142, ISSN: 0004-0428 